Francisco Pereira Neto - O lugar Afro-brasileiro na guerra...

\title{
O LUGAR AFRO-BRASILEIRO NA GUERRA: SINCRETISMO E RELIGIOSIDADE
}

Francisco Pereira Neto*

Penso que o tema proposto pelo texto do professor Ari Pedro Oro $^{1}$ nos remete a uma das discussões contemporâneas mais vigorosas no campo das religiões populares. Os contornos que especialmente o avanço das igrejas pentecostais tem apresentado nas últimas décadas vêm produzindo grande visibilidade para os fenômenos da religiosidade popular, além de demonstrar formas de organização e estratégias de expansão pouco comuns a esse campo de expressão religiosa. Até o momento, o campo das chamadas religiões populares era marcado por uma forma de organização que destoava das características organizacionais das concebidas como igrejas oficiais, fato que demonstrava formas de reprodução claramente diferenciadas. É o que demonstram as diferenças entre as igrejas católicas e protestantes em relação as religiões afrobrasileiras e, em menor medida, ao espiritismo, e mesmo as diferenças entre catolicismo popular e catolicismo oficial. Em termos teóricos, essa realidade centralizava os debates em tomo das visões evolucionistas da religião (Frazer, Durkheim), em especial aquelas que classificavam os diferentes fenômenos religiosos como magia ou religião, conferindo, evidentemente, a supremacia da segunda ordem de fenômenos em termos de expressão social.

As novidades que a realidade do neopentecostalismo nos apresenta sugere mudanças importantes nos marcos interpretativos utilizados para a analise das religiões populares, como, por exemplo, a vinculação da religiosidade popular a uma expressão exclusiva de grupos de baixa renda da sociedade brasileira. Se pensarmos na

* Doutorando do PPGAS - UFRGS, prepara tese sobre religião e política. A dissertação de mestrado defendida no PPGAS - UFRGS, tem como titulo: A Caminho da Luz: estudo sobre o espiritismo e modernidade em Cascavel, Oeste do Paraná.

1Os comentários deste ensaio são considerações ao texto do professor Ari Pedro Oro, "Neopentecostais e afro-brasileiros: quem vencerá essa guerra?".

Debates do NER, Porto Alegre, ano 1, n. 1, p. 69-76. Novembro de 1997. 
origem escrava das religiões afro-brasileiras e na sua luta para desenvolve-se construindo estratégias de expressão entre os grupos marginalizados da sociedade, e bem possível reforçar essa hipótese. Por outro lado, se atentarmos para o desenvolvimento do espiritismo e da própria umbanda, veremos que essa exclusividade de setores de baixa renda na constituição religiosidade popular não se verifica. No caso do neopentecostalismo, mesmo com a presença maciça de setores de baixa renda, é visível que esse movimento religioso não se reduz a essa esfera social.

Porém, o ponto mais significativo que a realidade do neopentecostalismo impõe para a discussão sobre religiões populares é o fato de sua organização diferenciar-se dos modelos apresentados pelo catolicismo popular, pelas religiões afro-brasileiras e mesmo pelo espiritismo. Para determo-nos na discussão do professor Oro, a Igreja Universal do Reino de Deus pauta seu desenvolvimento numa organização burocrática onde existe uma definição estável de funções e posições hierárquicas e onde, principalmente, aparece a autoridade centralizada na figura do Bispo Macedo. Essa configuração é muito diferente da apresentada por outras religiões populares, que normalmente baseiam sua organização e expansão religiosa num modelo descentralizado, pautado pela autonomia dos grupos religiosos. Mesmo o catolicismo popular, que é um movimento religioso inserido no contexto de autoridade da hierarquia da igreja católica, também reproduz uma série de tensões com essa mesma hierarquia ao insistir numa certa autonomia na produção de seus bens simbólicos religiosos.

Baseado nesta distinção que o neopentecostalismo apresenta é que eu gostaria de discutir a guerra entre IURD e afro-brasileiros, tentando levantar algumas questões sobre o significado do processo de disputa para os contendores. A meu ver, é significativo que uma das partes, os afro-brasileiros, não estejam muito dispostos a uma "guerra".

Para quem observa um pouco mais detidamente a presença da IURD, facilmente percebe que sua expressão esta fortemente pautada na utilização dos meios de comunicação de massa, especialmente o rádio e a televisão. A evidência de tal prioridade é o fato da organização religiosa do Bispo Macedo ser proprietária de redes de rádio e televisão. Além dos programas religiosos veiculados

Debates do NER, Porto Alegre, ano 1, n. 1, p. 69-76. Novembro de 1997. 
pela IURD, há uma presença marcante em noticiários e documentários das redes comerciais "laicas", nos quais normalmente suas atividades aparecem marcadas negativamente. A administração do dinheiro na IURD e os espetáculos de exorcização que promove são os principais elementos de crítica. Porém, outro fato que chama a atenção - mas, como lembra o professor Ari Oro, não e repercutido nos meios de comunicação - é a constante e quase exclusiva referência a deuses e espíritos afro-brasileiros como elementos de demonização. Diante da insistência e virulência dos ataques produzse uma certa perplexidade com a aparente não reação dos membros das religiões afro-brasileiras. O texto do professor Oro nos traz algumas luzes sobre o problema, das quais eu gostaria de ressaltar algumas delas.

Do ponto-de-vista estritamente político não é demasiado lembrar que a história da constituição das religiões de origem africana no Brasil sempre esteve marcada por perseguições da igreja católica e do Estado a sua liberdade de expressão. Em última instância, a religiosidade afro-brasileira representava um dos principais meios de expressão cultural dos escravos negros, o grupo mais baixo na hierarquia social dos períodos colonial e imperial. Evidentemente que as marcas de negatividade não se dissolvem no período republicano posterior, quando as formas de repressão tomam outros contornos, mas subsistem. Portanto, não é preciso ter muita imaginação histórica para intuir a necessidade da constituição de uma série de estratégias por parte dos afro-brasileiros para reproduzir suas formas de expressão cultural, fundamentais para a manutenção de suas identidades. No contexto a que estamos nos reportando, a situação era de possibilidade de ataques diretos as instituições religiosas afro-brasileiras, os quais em muitos momentos ocorreram sistematicamente. Nestes casos, diante da desigualdade de forças, muito mais que uma guerra tínhamos perseguições.

Se o relatado tem um mínimo de realidade histórica, é legítimo perguntar-se como essas expressões religiosas mantiveramse vigorosas tais como se apresentam hoje em dia nos quadros da cultura de nossa sociedade urbano-industrial. Para levantar algumas pistas para esse problema é interessante resgatar algumas declarações de praticantes das religiões afro-brasileiras contidas no texto do professor Ari Oro, quando questionados sobre a passividade dos

Debates do NER, Porto Alegre, ano 1, n. 1, p. 69-76. Novembro de 1997. 
afro-brasileiros diante dos ataques da IURD. Dilci da Oxum e Adalberto Pernambuco Nogueira, por exemplo, indicavam que essas questões seriam resolvidas através da intervenção dos deuses e orixás, sem a necessidade dos seus membros entrarem numa disputa explícita. Talvez confiante nessa forma de resolver os conflitos, o pai-de-santo baiano Aristides Mascarenhas confere pouca importância aos ataques da IURD, lembrando o passado de perseguições das religiões afro-brasileiras.

Para entender essas manifestações e necessário lembrar de algumas características importantes presentes na visão de mundo e na organização das religiões afro-brasileiras ${ }^{2}$. Em primeiro lugar, destacar as características individualizantes das religiões afrobrasileiras, como bem lembrou o professor Ari Oro em seu artigo. Grande parte da atividade religiosa nos terreiros e centros está voltada para a garantia do bem-estar individual dos filhos de santo e clientes eventuais, quando especialmente o pai-de-santo, conhecedor dos mecanismos de intervenção com os deuses, deve garantir o sucesso das demandas. A realidade constantemente recriada nos rituais afro-brasileiros é a de um espaço de relações sociais dinâmico e conflituoso, onde os desejos de diferentes personalidades se relacionam não poucas vezes de forma conflituosa. Se nos atentarmos para as narrativas dos mitos, nas quais os mesmos são constantemente recriados em novas interpretações, veremos que as características humanizadas dos deuses sempre tematizam o drama da convivência dos desejos de personalidades diversas. Portanto, na visão de realidade presente nas cosmologias das religiões afrobrasileiras, o conflito, a manipulação da situação para prejudicar adversários conscientes ou inconscientes, são elementos que estão dentro de seus conceitos de ordem ou desordem. o que me parece importante pensar é que o espaço legitimo e eficaz para resolver esses conflitos é o da ordem do sagrado, do sobrenatural. Especialmente daqueles conflitos em que nominalmente estão envolvidas disputas no terreno do sobrenatural, casos de violência

2 A literatura sobre religiões afro-brasileiras e vasta. A titulo de sugestão, lembrarei algumas obras que podem ajudar no reconhecimento deste campo de estudos: Velho, Çvonne M. ÃooGuerra de Orixa; Dantas, Beatriz Goo Vovo Nago e Papai Branco; Prandi, Reginaldo. Os Candombles de São Paulo; Correa Norton F.. o Batuque do Rio Grande do SuI; Oro, Ari P. (org.). As Religiões Afro-brasileiras do Rio Grande do SuI.

Debates do NER, Porto Alegre, ano 1, n. 1, p. 69-76. Novembro de 1997. 
simbólica, como é o das perseguições da IURD.

Do ponto de vista das organizações religiosas, as características levantadas acima são importantes para entender a própria expansão dos cultos afro-brasileiros. Para um pai-de-santo é fundamental o prestígio conferido por sua capacidade de manipular com os deuses e, conseqüentemente, adquirir força através do sobrenatural. São comuns nos relatos de pais-de-santo narrativas que envolvem disputas com outros pais-de-santo que levaram o adversário à morte, evidentemente em função de sua capacidade de articular com a força dos deuses. Esse discurso de competência do pai-de-santo é importante para que ele tenha um grande número de seguidores, uma vez que seu prestigio está diretamente relacionado com sua capacidade de convencimento dos filhos-de-santo quanto ao seu poder de interferir nos acontecimentos das suas vidas cotidianas.

É comum a discordância entre os filhos-de-santo a respeito do poder do pai-de-santo, dos seus procedimentos rituais, da forma como trata sua família de santo privilegiando alguns filhos em detrimento de outros. Tais conflitos regularmente geram a mudança de terreiro do filho-de-santo descontente, ou mesmo a formação de um novo terreiro com a transferência de um grupo de pessoas. Como se vê, apesar do sentido individualizante proposto pela ação religiosa nos grupos afro-brasileiras, os cultos afro-brasileiros são fortemente dependentes de uma noção de grupo e de práticas coletivas de celebração religiosa. A questão é que o coletivo nunca é explicitamente sacralizado, sendo o equilíbrio do grupo dependente da administração dos comportamentos individuais, inclusive do paide-santo. Nesse sentido é possível entender o caráter descentralizador da organização religiosa dos grupos afro-brasileiros, onde os terreiros sustentam grande autonomia e as iniciativas de organização de estruturas centralizadas para coordenar as atividades dos terreiros é sempre uma atividade fadada ao fracasso.

Levando em conta essas caracterizações, fico tentado a pensar que o "campo da guerra religiosa" no qual a IURD propõe a disputa não é legitimo ou mesmo significativo para os praticantes das religiões afro-brasileiras. Como o professor Ari Oro ressaltou, o fato dos rituais de demonização da IURD atacarem deuses não individualizados das religiões afro-brasileiras faz com que, do ponto de vista dos praticantes das religiões afro-brasileiras, essas agressões

Debates do NER, Porto Alegre, ano 1, n. 1, p. 69-76. Novembro de 1997. 
não sejam capazes de representar uma ameaça real, ou pelo menos que sejam dignas de uma resposta radical. A desvalorização dos seus deuses como entidades abstratas promovida pela demonização da IURD, distante do seu nicho de atualização de significado representado pela experiência individual de seus praticantes, pode ser tomada como mais uma entre outras iniciativas de perseguição de seus deuses. Para reforçar minhas hipóteses e a título de comparação, é interessante perceber a diferença de reação provocada pelo famoso episódio do "chute na santa" relatado no texto do professor Oro, demonstrando diferenças nos processos de atualização do significado quando comparamos símbolos religiosos afro-brasileiros e católicos.

\section{Sincretismo e alteridade}

A titulo de conclusão dos comentários sobre o texto do professor Ari Oro gostaria de ressaltar uma questão que considero fundamental e que pode vir a transformar-se num campo de pesquisa profícuo. Refere-se as possibilidades de sincretismo entre a IURD e as religiões afro-brasileiras proposta por Oro na conclusão de seu trabalho:

"Enfim, sugiro, de um lado, que a guerra santa está provocando, até cerro ponto e em determinados aspectos, a "umbandização" da Igreja Universal, o que significa que quanto mais ela combate o inimigo mais dele se aproxima e com ele se identifica; e, de outro lado, que a guerra santa está forçando, também até certo ponto, as religiões afro-brasileiras a se institucionalizarem (segundo a sugestão de P. Beyer, 1997)³, o que significa que para fazer frente aos ataques Universais essas religiões talvez sejam levadas a adotarem um modelo institucional (cristão?), portanto, também se aproximando e se identificando, até certo ponto, com o inimigo". (Oro, 1997:23)

As possibilidades de pesquisa estimuladas pela sugestão do professor Ari Oro são múltiplas e complexas, das quais pretendo destacar alguns pontos. Em primeiro lugar, creio ser importante uma

3 Beyer, Peter. The City and beyond as dialogue: negotiating, religious authenticity in global society. Paper apresentado no congresso da Intemational Society for the Sociology of Religion, Toulouse, 7-11 dejulho de 1997.

Debates do NER, Porto Alegre, ano 1, n. 1, p. 69-76. Novembro de 1997. 
discussão mais aprofundada da natureza desse processo sincrético, pois parece-me que os fluxos de influência para uma e outra religião tem intensidades diferentes, assim como é possível encontrar uma reelaboração diferenciada dos elementos culturais inseridos no contexto das duas organizações religiosas. Deve-se lembrar que o recurso aos símbolos afro-brasileiros é um elemento central na organização dos rituais da IURD, como foi amplamente destacado no texto do professor Oro, mostrando que, de certa forma, os neopentecostais e os afro-brasileiros compartilham de um mesmo campo semântico. Num exercício de radicalização teórica do fenômeno poder-se-ia dizer que a presença de elementos afrobrasileiros nos rituais da IURD não constituiriam propriamente num exercício de alteridade, vista como o encontro de campos semânticos diferentes, mas numa proposição de contraste com o objetivo de definir identidades divergentes dentro de um mesmo campo semântico. Assim, neste ponto de vista, se tivermos em conta as características organizacionais das duas religiões, o sistema dos Universais é mais dependente dos elementos culturais dos afrobrasileiros.

Por outro lado, o sentido oposto dos fluxos sincréticos, ou seja, aquele da IURD para as religiões afro-brasileiras, parece ser de menor intensidade. Tendo presente os elementos que levantei acima sobre as características da organização descentralizada das religiões afro-brasileiras, penso ser necessário ver com algumas reservas o processo de institucionalização das religiões afro-brasileiras, especialmente se esse for visto com referência no modelo baseado na composição "technical" identity/global cultural models proposto por Beyer (1997) para as religiões na modernidade. Mesmo reconhecendo a necessidade de sutilizar a dicotomia global/local das teorias da globalização, principalmente no que elas refletem em termos de relações de poder, me parece que insistir na definição de um modelo de institucionalização necessário ("technical" identity) para que as religiões se reproduzam em condições de modemidade globalizada pode levar a reprodução das relações de poder criticadas pelo autor quando ele analisa a produção sobre globalização. Mesmo que o modelo proposto por Beyer dilua a oposição centro/periferia, e a conseqüente determinação do primeiro elemento na definição do modelo, propõe modelos organizativos que representariam a religião

Debates do NER, Porto Alegre, ano 1, n. 1, p. 69-76. Novembro de 1997. 
na modernidade; ou seja, expressa uma concepção evolucionista do desenvolvimento social.

No caso específico da influência da IURD nas religiões afrobrasileiras, creio que a adoção das formas institucionais da primeira pelas segundas levaria a criação de uma outra religião, na medida em que dificilmente as chamadas religiões afro-brasileiras deixariam de representar um modelo cultural tal qual representam atualmente ${ }^{4}$.

O segundo ponto a ser destacado na verdade é uma proposta de abordagem para o problema do sincretismo que considero bastante promissora. Estou pensando especificamente no trabalho de Birman $^{5}$ sobre as "passagens" entre os cultos de possessão e os neopentecostais. A autora procura entender essa interlocução entre as diferentes religiões dando ênfase em dois níveis: "(...) no primeiro, no plano do individuo, em que este redefine seu lugar e identidade religiosa e sua forma de pensar a si próprio na relação com a esfera do sobrenatural; no segundo, no plano das relações sociais, em que destacamos algumas mediações que são construídas entre estes dois cultos por seus fiéis" (Birman,1996:93). Penso que a abordagem de Birman tem a vantagem de ocupar-se do importante fenômeno do trânsito religioso na sociedade brasileira através de uma rediscussão do problema da conversão, onde a adesão religiosa não implica numa submissão exclusiva do individuo a religião que pratica. Para explorar esta área nebulosa e profícua das diferentes formas e estratégias da adesão religiosa a autora lança mão das concepções de Sahlins sobre o contato cultural. Segundo Birman (1996: 92), esse autor " ... atribui uma clara positividade ao desentendimento e ao confronto de interpretarções gerados no contato cultural" - é o que conceitualmente denomina como mal-entendido produtivo.

No meu ponto-de-vista, para tratar do problema do sincretismo, esse tipo de abordagem complementaria uma perspectiva institucional do problema.

4 Sobre a capacidade de expansão das religiões afro-brasileiras além fronteiras, é interessante ver Oro, Ari. (1994) "Difusão das religiões afrobrasileiras do Rio Grande do Sul para os países do Prata". In: Oro (org.) As Religiões Afro-brasileiras do Rio Grande do Sul, sobre a expansão dessas religiões para o Uruguai e a Argentina.

5 Birman, Patricia. "Cultos de possessão e pentecostalismo no Brasil: passagens". Religião e Sociedade 17/1-2,1996.

Debates do NER, Porto Alegre, ano 1, n. 1, p. 69-76. Novembro de 1997. 